Research Article

\title{
Valorization of Glycine max (Soybean) Seed Waste: Optimization of the Microwave-Assisted Extraction (MAE) and Characterization of Polyphenols from Soybean Meal Using Response Surface Methodology (RSM)
}

\author{
Cerile Ypolyte Woumbo (D), Dieudonné Kuate $\mathbb{D}$, Mathilde Julie Klang, \\ and Hilaire Macaire Womeni
}

Research Unit of Biochemistry of Medicinal Plants, Food Science and Nutrition, University of Dschang, Dschang, Cameroon

Correspondence should be addressed to Dieudonné Kuate; dieudonne.kuate@univ-dschang.org

Received 9 August 2021; Accepted 29 October 2021; Published 23 November 2021

Academic Editor: Ana Angelica Feregrino-Perez

Copyright (C) 2021 Cerile Ypolyte Woumbo et al. This is an open access article distributed under the Creative Commons Attribution License, which permits unrestricted use, distribution, and reproduction in any medium, provided the original work is properly cited.

\begin{abstract}
The present study aimed at determining the optimal conditions for extraction of total phenolic compounds from soybean (Glycine max) meal, a by-product of the soybean seeds industry, using a green protocol with microwave-assisted extraction (MAE). A facecentered composite design (FCCD) was used for optimization. Based on a screening aimed to determine the factors that significantly influenced the responses, a 50\% hydro-ethanolic solution was used with solvent/dry matter ratio (60/1-110/1), power $(120-270 \mathrm{~W})$, and time $(0-10 \mathrm{~min})$ as factors, while the responses studied were total phenolic and flavonoid contents. FTIR, TLC, $\mathrm{DPPH}$, and FRAP anti-oxidants tests were used to characterize the extracts obtained with optimum conditions. The factors that significantly influenced both responses were the individual effect of all factors, the interaction between solvent/dry matter ratio and extraction time, the quadratic effect of solvent/dry matter ratio, and power for total phenolic content, while only the quadratic effect of power significantly influenced the flavonoid content. The highest contents of phenols (13.09 mg GAE/g) and flavonoid $(7.39 \mathrm{mg} \mathrm{CE} / \mathrm{g})$ were obtained at $120 \mathrm{~W}$ for $0.16 \mathrm{~min}$ with a solvent/dry matter ratio of $60 / 1$. ATR-FTIR spectra indicated the presence of polyphenolic compounds in the extract, namely flavonoids. TLC indicated the presence of at least nine compounds in the extract, among which catechin and quercetin were identified with respective Rf of 0.98 and 0.93 . DPPH assay showed the antioxidant capacity for the extract with an $\mathrm{IC}_{50}$ of $194.98 \mu \mathrm{g} / \mathrm{ml}$. RSM permitted us to develop a green protocol for maximum extraction of polyphenols from soybean seeds waste using less solvent, low power, and a reduced time in MAE.
\end{abstract}

\section{Introduction}

Soybean meal is a by-product of the soybean seed industry, which is commonly used for animal feeding $[1,2]$ or rejected directly in nature, then causing serious problems to municipalities and to the environment $[3,4]$. In order to reduce pollution related to soybean seed industry's by-products and wastes, numerous usages have been proposed and tested: broiler breeding [1], growing substrate or source of specific compounds for microorganisms $[3,5]$, biosurfactants [6], and biodiesel production among others. But soybean waste and meal particularly have not been exploited for the production of polyphenols. Soybean (Glycine max) seeds have been reported as one of the richest flavonoid legume sources known nowadays; with up to $3 \mathrm{mg} / \mathrm{g}$ dry weight [7], these compounds are not totally destroyed during the different treatments that seeds undergo and may find themselves in soybean meal discarded by industries. Phenolic compounds have multiple applications in nutraceutical and pharmaceutical domains [8]. Flavonoids, for example, and isoflavones precisely are particularly abundant in soybean seeds and have long been exploited for their anti-oxidants, anti-inflammatory, and anti-cancer activities, among others [9]. Exigencies of green chemistry nowadays appeal to 
researchers to use "green" processes in science [10]. Recently, the use of supercritical fluid, ultrasound-assisted extraction (UAE), and microwave-assisted extraction (MAE) methods for extraction of phenols has contributed enough to reduce the cost of production and pollution and improve extraction yield $[11,12]$. MAE is said to be the most effective in terms of polyphenol yield, accessibility, greenest, and respect to the environment $[13,14]$. Literature has shown that yields of MAE are conditioned by many factors including the nature of the extracting solvent, time of extraction, power of the equipment, dry matter/solvent ratio, and the nature of the matrix [15]. So the determination of experimental conditions for extraction of the highest polyphenolic content from soybean meal using a green protocol will be helpful, since these seeds are among the richest sources of the named compounds. This study aimed at determining the optimal conditions for extraction of phenolic compounds from soybean meal, a soybean seed industry waste product, using a face-centered composite design in the response surface methodology with MAE.

\section{Materials and Methods}

\subsection{Materials}

2.1.1. Plant Material. Seeds of Glycine max (variety TGX1850-10E) were said to have been obtained from "Institut de RechercheAgricole pour le Developpement" (IRAD), Foumbot (latitude: $5^{\circ} 30^{\prime} 29^{\prime} \mathrm{N}$, longitude: $10^{\circ} 38^{\prime} 12^{\prime} \mathrm{E}$, and altitude: $1,054 \mathrm{~m}$ ).

2.1.2. Chemical. Ethanol $\left(95^{\circ}\right)$ and methanol were obtained from the local pharmacy. Ethyl acetate and formic acid were obtained from Sigma.

\subsection{Methods}

2.2.1. Preparation of Sample Soybean Meal. Soybean meal used was obtained from a local oil refinery situated in Foumbot. The meal was brought to the laboratory in a plastic bag and dried to constant weight at $45^{\circ} \mathrm{C}$ using an air oven.

2.2.2. Screening of Factors Affecting the Phenol and Flavonoid Contents. On the basis of the literature, variables retained for screening were: time of extraction, dry matter/solvent ratio, proportion of ethanol, and power $[16,17]$. Factors influencing the yields of phenols and flavonoids were determined from Table 1.

2.2.3. Extraction of Phenolic Compounds. For each trial, $1 \mathrm{~g}$ of soybean meal was mixed in a beaker with the appropriate amount of solvent according to the experimental conditions as given by the chosen design. The mixture was stirred using a magnetic agitator; afterward, it was allowed to rest for 10 minutes at room temperature and put in a microwave oven (SAMSUNG M735) for extraction, under specified conditions. Samples were centrifuged $(4,000 \mathrm{rpm} / 5 \mathrm{~min})$, and the supernatant was collected after filtration through Watman paper no. 1. The solvent was then evaporated in an air oven at $45^{\circ} \mathrm{C}$ until obtention of the dry extract. Dry extracts were immediately used for the determination of total phenolic and flavonoid contents.

2.2.4. Determination of Total Phenolic Content. The total phenolic content was assessed according to the method proposed by Dohou et al. [1]. Briefly, $0.2 \mathrm{ml}$ of Folin-Ciocalteu reagent (tenfold diluted) was added to a tube containing $0.01 \mathrm{ml}$ of plant extract $(5 \mathrm{mg} / \mathrm{ml})$ and $1.39 \mathrm{ml}$ of distilled water. The mixture was allowed to stand for 3 minutes before adding $0.4 \mathrm{ml}$ of sodium carbonate $(20 \% \mathrm{w} / \mathrm{v})$ and then mixed using a vortex. The tube was then incubated at $40^{\circ} \mathrm{C}$ for $20 \mathrm{~min}$ in a water bath, and absorbance was read at $760 \mathrm{~nm}$ against a blank using a BIOMATE spectrophotometer. Gallic acid $(0.2 \mathrm{~g} / \mathrm{l})$ was used to draw a calibration curve. All experiments were carried out in triplicate, and results were expressed as mg of gallic acid equivalent (GAE) per gram of dry extract (mg GAE/g dry weight).

2.2.5. Determination of Flavonoid Content. Flavonoid content was obtained using the method described by Padmadja et al. [18]. A volume $(0.03 \mathrm{ml})$ of sodium nitrite $(5 \%)$ was added to a tube containing $1.49 \mathrm{ml}$ of water and $0.1 \mathrm{ml}$ of extract solution $(5 \mathrm{~g} / \mathrm{ml})$. After $5 \mathrm{~min}$, a volume $(0.003 \mathrm{ml})$ of aluminum chloride (10\%) was added to the tube, and the mixture was allowed to rest for $6 \mathrm{~min}$. Afterward, $0.3 \mathrm{ml}$ of $\mathrm{NaOH}(1 \mathrm{M})$ and $0.24 \mathrm{ml}$ of water were introduced, respectively, in the tube and mixed with a vortex before absorbance was read using a BIOMATE spectrophotometer at $510 \mathrm{~nm}$ against a blank. Calibration curve was made using catechin. All experiments were made in triplicate, and the results were expressed as $\mathrm{mg}$ of catechin equivalent per $\mathrm{g}$ of dry extract (mg CE/g of dry weight). Figure 1 depicts the flowchart of the whole work.

2.3. Optimization of the Responses Using the Central Composite Design. Factors such as time of extraction, dry matter/solvent ratio, and power were observed to influence the responses. A face-centered composite design was used, and the studied responses were total phenolic content $\left(\mathrm{Y}_{1}\right)$ and flavonoid content $\left(\mathrm{Y}_{2}\right)$. Ranges of different factors were taken according to the results of preliminary experiments. Experiments were randomized, and responses were evaluated in triplicate. The proposed model is as follows:

$$
\begin{aligned}
Y= & a_{0}+a_{1} X_{1}+a_{2} X_{2}+a_{3} X_{3}+a_{11} X_{1}^{2}+a_{22} X_{2}^{2} \\
& +a_{33} X_{3}^{2}+a_{12} X_{1} X_{2}+a_{13} X_{1} X_{3}+a_{23} X_{2} X_{3},
\end{aligned}
$$

where $Y$ is the response (total phenolicor flavonoid content); $X_{1}, X_{2}$, and $X_{3}$ are the studied factors; $a_{0}$ is the offset term, while $a_{1}, a_{2}$, and $a_{3}$ are linear effects; $a_{11}, a_{22}$, and $a_{33}$ are the quadratic effects; and $a_{12}, a_{13}, a_{14}, a_{23}$, and $a_{34}$ are interaction effects. All experiments carried out are summarized in Table 2. Ranges are as follows: solvent/seed ratio (ml/g): 59.77/1-110.22/1; power (W): 119.31-270.78 and time (min): $0.04-10.04$. 
TABLE 1: Screening plan.

\begin{tabular}{|c|c|c|c|c|}
\hline Variable & Experiments & 1 & 2 & 3 \\
\hline \multirow{4}{*}{ Power } & Power (W) & 120 & 180 & 240 \\
\hline & Time (min) & 5 & 5 & 5 \\
\hline & Ethanol percentage (\%) & 20 & 20 & 20 \\
\hline & Solvent/dry matter ratio $(\mathrm{ml} / \mathrm{g})$ & $30 / 1$ & $30 / 1$ & $30 / 1$ \\
\hline \multirow{4}{*}{ Time } & Power $(\mathrm{W})$ & 240 & 240 & 240 \\
\hline & Time $(\min )$ & 2 & 4 & 6 \\
\hline & Ethanol percentage (\%) & 20 & 20 & 20 \\
\hline & Solvent/dry matter ratio $(\mathrm{ml} / \mathrm{g})$ & $30 / 1$ & $30 / 1$ & $30 / 1$ \\
\hline \multirow{4}{*}{ Ethanol percentage } & Power $(\mathrm{W})$ & 240 & 240 & 240 \\
\hline & Time $(\min )$ & 5 & 5 & 5 \\
\hline & Ethanol percentage (\%) & 20 & 50 & 80 \\
\hline & Solvent/dry matter ratio $(\mathrm{ml} / \mathrm{g})$ & $30 / 1$ & $30 / 1$ & $30 / 1$ \\
\hline \multirow{4}{*}{ Solvent/dry matter ratio } & Power $(\mathrm{W})$ & 240 & 240 & 240 \\
\hline & Time $(\min )$ & 5 & 5 & 5 \\
\hline & Ethanol percentage (\%) & 20 & 20 & 20 \\
\hline & Solvent/dry matter ratio $(\mathrm{ml} / \mathrm{g})$ & $20 / 1$ & $30 / 1$ & $40 / 1$ \\
\hline
\end{tabular}

2.4. Characterization of the Extract. FTIR, TLC, DPPH, and FRAP anti-oxidant assays were carried out on the polyphenolic-rich extract obtained with the optimum conditions.

2.4.1. Fourier-Transform Infrared Spectroscopy (FTIR). Soybean meal extract was analyzed by a Fourier-transform infrared (FTIR) apparatus coupled with an attenuated total reflectance (ATR) accessory. Spectra were collected at frequency regions of 4,000-400 $\mathrm{cm}^{-1}$ using an FTIR spectrometer (Alpha, Bruker, Germany) on a diamond plate at a resolution of $4 \mathrm{~cm}^{-1}$. Two replicates spectra of 50 scans were recorded. Raw spectra were corrected.

2.4.2. Thin-Layer Chromatography (TLC). TLC was performed using a precoated plate covered with $60 \mathrm{~F} 250$ silica gel (MERCK). Plates of $5 \times 8 \mathrm{~cm}$ were used and activated at $105^{\circ} \mathrm{C}$ for $30 \mathrm{~min}$. Two milligram of the extract were dissolved in $10 \mathrm{ml}$ water and centrifuged for $10 \mathrm{~min}$ at $3,500 \mathrm{rpm}$. Ten microliter of supernatant was deposited on the plates using a capillary tube. Two standards were used, namely catechin and quercetin (1 mg dissolved in $50 \mathrm{ml}$ of ethanol, centrifuged, and supernatant used). Development was done for $20 \mathrm{~min}$ in a presaturated $(30 \mathrm{~min})$ rectangular development chamber. The mobile phase was made of ethyl acetate/formic acid/glacial acetic acid/water (96/11/11/30). After development $(6.5 \mathrm{~cm})$, the plate was removed and dried at $45^{\circ} \mathrm{C}$ in an air oven for $1 \mathrm{~min}$, before visualization under UV light $(254 \mathrm{~nm})$. Bands were circled, and Rf calculated.

2.4.3. Anti-Oxidant Assay. DPPH radical scavenging activity of the extract was determined using the method described by Mensor et al. [19], while the ferric reducing assay power (FRAP) was performed as described by Oyaizu [20].

\section{Statistical Analysis}

Designing and analysis of the results were done using Minitab 18. Experiments were carried out in triplicate. Statistical significance of the model variables was determined at a $5 \%$ probability level. Main effects and contour plots were plotted using Sigma Plot v11.0 (c) systat. Data on phenol and flavonoid contents were expressed as mean \pm SD and compared using the Bonferroni test with the software SPSS version 22 .

\section{Results and Discussion}

4.1. Screening Factors. Results of the screening factors are indicated in Table 3: usage of high power leads to a reduction in both the total phenolic and flavonoid contents of the extracts. Long cooking time almost induced a linear reduction of the two studied responses. Short times were seen to be best for the highest responses. Variation of ethanol percentage in the extracting solvent showed the highest TPC and TFC at $50 \%$. That observation means water/ethanol (50/50) may be more effective in extracting polyphenol from soybean meal. We noticed the effect of the dry matter/solvent ratio that any increase in the solvent proportion leads to an increase in total phenolic and flavonoid contents.

While testing the influence of any factor, the others were, respectively, kept constant at: power $(180 \mathrm{~W})$, time (5 min), solvent/dry matter ratio (30/1), and ethanol proportion (20\%).

4.2. Optimization of the Responses Using the Central Composite Design. Results of the screening permitted the optimization of the process using three main factors for extraction of phenolic compounds from soybean meal, namely the microwave power, the cooking time, and the solvent/dry matter ratio. Ethanol proportion was decided to 


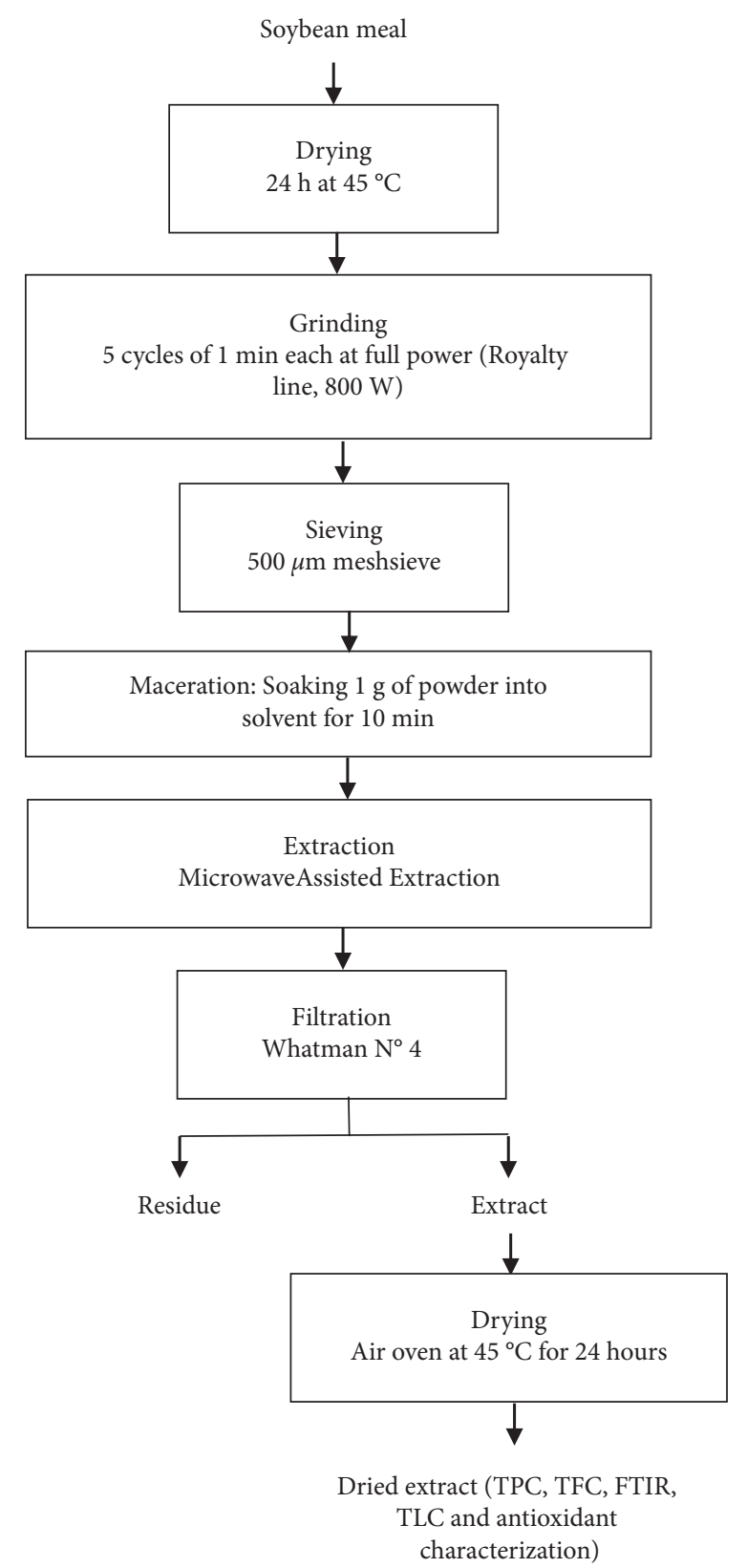

FIGURE 1: Extraction flow chart of phenolic compounds from soybean meal. TPC: total phenolic content, TFC: total flavonoid content, FTIR: Fourier-transform infrared, and TLC: thin-layer chromatography.

be $50 \%$, since we noticed a maximal production with $50 \%$ ethanol proportion (in the solvent) of TPC and TFC during the screening. Also, the literature indicates that dielectric properties of the solvent should be highly taken into consideration when planning to extract phenolic compounds using MAE. Compared to water, ethanol or its mixtures with water have a lower dielectric constant and are more transparent to microwave, thus not well converting them into heat. But its high capacity to dissolve and extract phenolic compounds [21-23] and its greenness oriented the choice of a hydro-ethanolic solution as extracting solvent. Table 4 gives the different factors retained for optimization, in coded and real values with experimental and predicted values of the responses.

4.3. Analysis of Main Effects. The entire experimental plan consisted of 20 trials. The highest total phenolic content $(6.87 \mathrm{mg}$ of $\mathrm{GAE} / \mathrm{g})$ was obtained at $150 \mathrm{~W}$ for $2 \mathrm{~min}$ of cooking time with $70 \mathrm{ml}$ of solvent. The lowest content $(1.75 \mathrm{mg} \mathrm{GAE} / \mathrm{g})$ is observed at $240 \mathrm{~W}$ of microwave power with $70 \mathrm{ml}$ of extracting solvent and a heating time of $8 \mathrm{~min}$. Concerning the flavonoid content, the highest value (4.46 mg QE/g) was obtained at $150 \mathrm{~W}$ of microwave power, 
TABLE 2: Experimental design in coded and real variables.

\begin{tabular}{|c|c|c|c|c|c|c|}
\hline \multirow{2}{*}{ Trials } & \multicolumn{3}{|c|}{ Matrix of coded variables } & \multicolumn{3}{|c|}{ Matrix of real variables } \\
\hline & $X_{1}$ & $X_{2}$ & $X_{3}$ & Solvent/meal ratio $(\mathrm{ml} / \mathrm{g})$ & Power (W) & Time (min) \\
\hline 1 & -1 & -1 & -1 & 70 & 150 & 2 \\
\hline 2 & 1 & -1 & -1 & 100 & 150 & 2 \\
\hline 3 & -1 & 1 & -1 & 70 & 240 & 2 \\
\hline 4 & 1 & 1 & -1 & 100 & 240 & 2 \\
\hline 5 & -1 & -1 & 1 & 70 & 150 & 8 \\
\hline 6 & 1 & -1 & 1 & 100 & 150 & 8 \\
\hline 7 & -1 & 1 & 1 & 70 & 240 & 8 \\
\hline 8 & 1 & 1 & 1 & 100 & 240 & 8 \\
\hline 9 & -1.68 & 0 & 0 & 59.77 & 195 & 5 \\
\hline 10 & 1.68 & 0 & 0 & 110.22 & 195 & 5 \\
\hline 11 & 0 & -1.68 & 0 & 85 & 119.31 & 5 \\
\hline 12 & 0 & 1.68 & 0 & 85 & 270.68 & 5 \\
\hline 13 & 0 & 0 & -1.68 & 85 & 195 & 0.04 \\
\hline 14 & 0 & 0 & 1.68 & 85 & 195 & 10.04 \\
\hline 15 & 0 & 0 & 0 & 85 & 195 & 5 \\
\hline 16 & 0 & 0 & 0 & 85 & 195 & 5 \\
\hline 17 & 0 & 0 & 0 & 85 & 195 & 5 \\
\hline 18 & 0 & 0 & 0 & 85 & 195 & 5 \\
\hline 19 & 0 & 0 & 0 & 85 & 195 & 5 \\
\hline 20 & 0 & 0 & 0 & 85 & 195 & 5 \\
\hline
\end{tabular}

Bold values are replicates of the center points.

TABle 3: Conditions and responses for the screening.

\begin{tabular}{lcc}
\hline & Experiment & 1 \\
\hline & Power & \\
W $(120 \mathrm{~W})$ & 1.9 & 0.8 \\
$\mathrm{~W}(180 \mathrm{~W})$ & 1.3 & 0.8 \\
$\mathrm{~W}(240 \mathrm{~W})$ & Time (min) & 1.3 \\
\hline & 2.9 & 0.7 \\
$\mathrm{~T}(2 \mathrm{~min})$ & 1.5 & 0.6 \\
$\mathrm{~T}(5 \mathrm{~min})$ & 1.3 & 1.2 \\
$\mathrm{~T}(8 \mathrm{~min})$ & Ethanol proportion \\
& 1.9 & 2.4 \\
$\mathrm{E}(20 \%)$ & 4.3 & 1.3 \\
$\mathrm{E}(50 \%)$ & 2.1 & 0.4 \\
$\mathrm{E}(80 \%)$ & Dry matter/solvent ratio \\
& 1.2 & 1.3 \\
$\mathrm{DM} / \mathrm{S}(30)$ & 3.9 & 1.8 \\
$\mathrm{DM} / \mathrm{S}(60)$ & 2.1 & \\
$\mathrm{DM} / \mathrm{S}(80)$ & & \\
\hline
\end{tabular}

2 min heating time with a solvent/dry matter ratio of $30 / 1$ $(\mathrm{ml} / \mathrm{g})$. The lowest flavonoid content $(1.25 \mathrm{mg} \mathrm{CE} / \mathrm{g})$ is obtained with $70 \mathrm{ml}$ of solvent at $150 \mathrm{~W}$ for a boiling time of $2 \mathrm{~min}$. Values ranging from 1.75 to $6.78 \mathrm{mg}$ of $\mathrm{GAE} / \mathrm{g}$ and $1.25 \mathrm{CE} / \mathrm{g}$ to $4.46 \mathrm{CE} / \mathrm{g}$ of extract for total phenol and flavonoid content were similar to those obtained by Malenčić et al. [24], Sakthivelu et al. [25], and Josipović et al. [26].

4.3.1. Effect of Solvent Ratio. Figure 2 shows that an increase in the solvent ratio induces an almost linear reduction in the total phenolic content of extracts when going from 60/1 to $80 / 1$ ( $\mathrm{ml}$ of solvent/g DW). But the responses measured started increasing as the solvent ratio passed from 90:1 to greater values. Such observations may be explained by the type of phenols extracted at each condition, since literature indicates that free or bound phenolic compounds are found in soybean and are not forcibly extracted in the same experimental conditions [16]. Nevertheless, it is well accepted nowadays that high solvent content increases mobility of compounds (mass transfer) from plants matrix, thus explaining the observed increase in the total phenolic content of extracts at a certain solvent ratio, since previous research had already reported that [27]. An increase in the solvent ratio only led to a progressive diminution of the flavonoid content. 
TABLE 4: Matrix of coded and real variables with responses obtained according to experimental conditions and predicted values.

\begin{tabular}{|c|c|c|c|c|c|c|c|}
\hline \multirow{3}{*}{ Trials } & \multirow{2}{*}{\multicolumn{3}{|c|}{ Matrix of real and coded variables }} & \multicolumn{4}{|c|}{ Responses } \\
\hline & & & & \multicolumn{2}{|c|}{ TPC (mg GAE/g) } & \multicolumn{2}{|c|}{ TFC (mg CE/g) } \\
\hline & Solvent & Power & Time & Exp & Pre & $\operatorname{Exp}$ & Pre \\
\hline 1 & $70(-1)$ & $150(-1)$ & $2(-1)$ & $6.87 \pm 0.14$ & 6.94 & $4.46 \pm 0.05$ & 4.25 \\
\hline 2 & $100(1)$ & $150(-1)$ & $2(-1)$ & $3.66 \pm 0.10$ & 3.87 & $3.31 \pm 0.07$ & 3.20 \\
\hline 3 & $70(-1)$ & $240(1)$ & $2(-1)$ & $4.87 \pm 0.09$ & 5.10 & $2.34 \pm 0.02$ & 2.61 \\
\hline 4 & $100(1)$ & $240(1)$ & $2(-1)$ & $1.96 \pm 0.17$ & 1.67 & $1.43 \pm 0.05$ & 1.29 \\
\hline 5 & $70(-1)$ & $150(-1)$ & $8(1)$ & $2.09 \pm 0.15$ & 2.83 & $1.25 \pm 0.15$ & 1.45 \\
\hline 6 & $100(1)$ & $150(-1)$ & $8(1)$ & $4.24 \pm 0.18$ & 4.46 & $2.11 \pm 0.05$ & 1.91 \\
\hline 7 & $70(-1)$ & $240(1)$ & $8(1)$ & $1.75 \pm 0.02$ & 1.99 & $1.70 \pm 0.07$ & 1.88 \\
\hline 8 & $100(1)$ & $240(1)$ & $8(1)$ & $2.89 \pm 0.09$ & 3.26 & $1.79 \pm 0.05$ & 2.07 \\
\hline 9 & $59.77(-1,68)$ & $195(0)$ & $5(0)$ & $6.21 \pm 0.11$ & 5.66 & $2.65 \pm 0.02$ & 2.40 \\
\hline 10 & $110.22(1.68)$ & $195(0)$ & $5(0)$ & $4.24 \pm 0.06$ & 4.14 & $1.55 \pm 0.07$ & 1.67 \\
\hline 11 & $85(0)$ & $119.31(-1.68)$ & $5(0)$ & $5.80 \pm 0.14$ & 5.27 & $3.21 \pm 0.10$ & 3.42 \\
\hline 12 & $85(0)$ & $270.68(1.68)$ & $5(0)$ & $2.83 \pm 0.11$ & 2.71 & $2.51 \pm 0.10$ & 2.18 \\
\hline 13 & $85(0)$ & $195(0)$ & $-0.04(-1.68)$ & $3.15 \pm 0.02$ & 3.23 & $2.80 \pm 0.02$ & 2.93 \\
\hline 14 & $85(0)$ & $195(0)$ & $10.04(1.68)$ & $1.84 \pm 0.09$ & 1.11 & $1.48 \pm 0.07$ & 1.23 \\
\hline 15 & $85(0)$ & $195(0)$ & $5(0)$ & $2.54 \pm 0.04$ & 2.43 & $1.85 \pm 0.02$ & 1.85 \\
\hline 16 & $85(0)$ & $195(0)$ & $5(0)$ & $2.42 \pm 0.05$ & 2.43 & $1.92 \pm 0.05$ & 1.85 \\
\hline 17 & $85(0)$ & $195(0)$ & $5(0)$ & $2.51 \pm 0.15$ & 2.43 & $1.84 \pm 0.02$ & 1.85 \\
\hline 18 & $85(0)$ & $195(0)$ & $5(0)$ & $2.30 \pm 0.05$ & 2.43 & $1.84 \pm 0.02$ & 1.85 \\
\hline 19 & $85(0)$ & $195(0)$ & $5(0)$ & $2.33 \pm 0.06$ & 2.43 & $1.82 \pm 0.05$ & 1.85 \\
\hline 20 & $85(0)$ & $195(0)$ & $5(0)$ & $2.39 \pm 0.06$ & 2.43 & $1.84 \pm 0.02$ & 1.85 \\
\hline
\end{tabular}

Bold values are replicates of the center points. Pre means predicted value, while Exp means experimental value.

4.3.2. Effect of Power. Figures 2 and 3 depict the influence of power on the total phenolic and flavonoid contents of extracts. We can see from the figures that an increase in the power induces a reduction in the phenol and flavonoid contents of the meal extracts. This could be the consequence of degradation of these compounds exposed to high temperature, since high power in microwave induce a quick elevation of the solvent temperature even when exposure is for a short duration. Đurović et al. [16] made a similar observation.

4.3.3. Effect of Time. From Figures 2 and 3, we can see that any increase in time of exposure also led to a diminution of the TPC and TFC of extracts because of progressive destruction of these thermo-sensitive compounds under long exposure to heat. Previous authors also noticed the same effect $[16,22,28]$.

4.4. ANOVA, Regression Equations for the Responses. Table 5 shows the ANOVA and the influence of each independent factor. We can see from the table that all independent factors significantly $(p<0.05)$ influenced both total phenolic and flavonoid contents. Quadratic effects of solvent ratio $\left(X_{1} X_{1}\right)$ and the power $\left(X_{3} X_{3}\right)$ significantly affected the total phenolic content of the extract obtained, while only the quadratic effect of the heating power $\left(X_{3} X_{3}\right)$ significantly influenced the flavonoid content of the extracts. Interaction between solvent ratio and the heating time $\left(X_{1} X_{2}\right)$ significantly impacted both the total phenolic and the flavonoid content, while only interaction between the time and the boiling microwave power $\left(X_{2} X_{3}\right)$ significantly affected the flavonoid content of the extracts. We can also see that interaction between solvent ratio and the heating time $\left(X_{1} X_{3}\right)$ contributed the most in the observed phenolic response $(24.74 \%)$, followed by the quadratic effect of the solvent ratio $\left(X_{1} X_{1}\right)$, which contributed up to $22.17 \%$ to the final response. Talking about the phenolic content, time $\left(X_{3}\right)$ and interaction between power and time $\left(X_{2} X_{3}\right)$ contributed the most to the observed response $(30.06 \%$ and $18.33 \%$, respectively).

The mathematical model predicting the influence of the solvent ratio, boiling time, and working power on the phenol and flavonoid contents of the extracts is given by the following equation:

$$
\begin{aligned}
\mathrm{TPC}= & 58.24-0.795 X_{1}-0.1213 X_{2}-2.693 X_{3} \\
& +0.003883 X_{1} X_{1}+0.000273 X_{2} X_{2}-0.0102 X_{3} X_{3} \\
& -0.000131 X_{1} X_{2}+0.02614 X_{1} X_{3}+0.00186 X_{2} X_{3}, \\
\mathrm{TFC}= & 19.86-0.0876 X_{1}-0.0836 X_{2}-1.715 X_{3} \\
& +0.000297 X_{1} X_{1}+0.000166 X_{2} X_{2}+0.00900 X_{3} X_{3} \\
& -0.000098 X_{1} X_{2}+0.00836 X_{1} X_{3}+0.003824 X_{2} X_{3} .
\end{aligned}
$$

\section{Assessment of Model Quality and Optimal Conditions}

Experimental values show us that these mathematical models can well explain the observed results. According to Joglekar and May [29], a good mathematical model should predict at least $75 \%$ of the responses; $R^{2}$ should then range from 0.75 to 1 . Our results give the determination coefficient for phenols and flavonoid, respectively, to be 0.95 and 0.94 , 


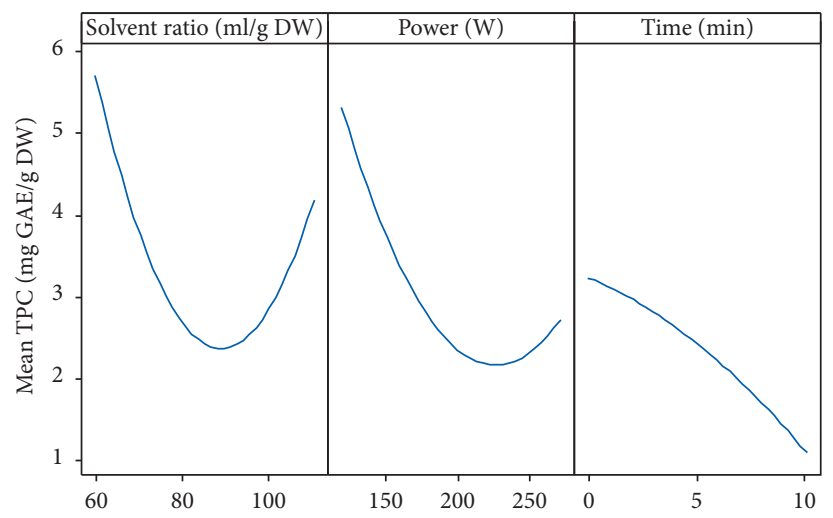

Figure 2: Effects of solvent/raw material ratio, power, and time on TPC.

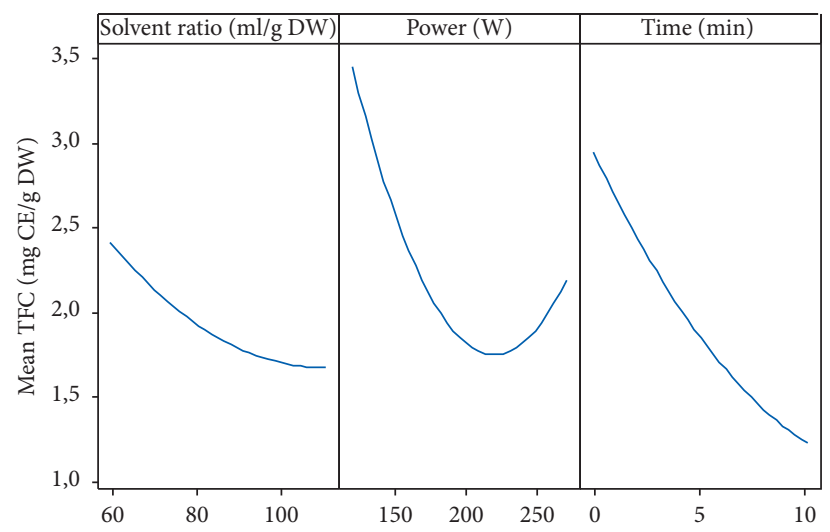

FIGURE 3: Effects of solvent/raw material ratio, power, and time on TFC.

TABle 5: Evaluation of quadratic model: $P$ value, F value, RC, CF (contribution factor, \%), AADM, and Bf for phenols and flavonoids.

\begin{tabular}{|c|c|c|c|c|c|c|c|c|}
\hline \multirow{2}{*}{ Source } & \multicolumn{3}{|c|}{ Total phenolic content } & \multicolumn{5}{|c|}{ Flavonoid content } \\
\hline & $P$ value & $F$ value & $\mathrm{RC}$ & CF (\%) & $P$ value & F value & $\mathrm{RC}$ & CF (\%) \\
\hline Solvent ratio $\left(X_{1}\right)$ & 0.005 & 12.76 & -0.795 & 6.18 & 0.011 & 9.74 & -0.087 & 5.52 \\
\hline Power $\left(X_{2}\right)$ & 0.001 & 36.45 & -0.121 & 17.65 & $\leq 0.001$ & 28.32 & -0.083 & 16.04 \\
\hline Time $\left(X_{3}\right)$ & 0.001 & 24.96 & -2.693 & 12.09 & $\leq \mathbf{0 . 0 0 1}$ & 53.08 & -1.715 & 30.06 \\
\hline$X_{1} \times X_{1}$ & $\leq 0.001$ & 50.79 & +0.003 & 22.72 & 0.346 & 0.98 & +0.000 & 0.11 \\
\hline$X_{2} \times X_{2}$ & 0.001 & 20.27 & +0.000 & 10.24 & 0.001 & 24.64 & +0.000 & 13.43 \\
\hline$X_{3} \times X_{3}$ & 0.473 & 0.56 & -0.010 & 0.27 & 0.258 & 1.44 & +0.009 & 0.81 \\
\hline$X_{1} \times X_{2}$ & 0.601 & 0.29 & -0.000 & 0.14 & 0.482 & 0.53 & -0.000 & 0.30 \\
\hline$X_{1} \times X_{3}$ & $\leq 0.001$ & 51.09 & +0.026 & 24.74 & 0.002 & 17.19 & +0.008 & 9.74 \\
\hline$X_{2} \times X_{3}$ & 0.158 & 2.33 & +0.001 & 1.13 & $\leq \mathbf{0 . 0 0 1}$ & 32.37 & +0.003 & 18.33 \\
\hline \multicolumn{9}{|c|}{ Validation of the model } \\
\hline$R^{2}$ & & 0.95 & & & & 0.94 & & \\
\hline AADM & & 0.00 & & & & 0.00 & & \\
\hline $\mathrm{Bf}$ & & 0.99 & & & & 0.99 & & \\
\hline
\end{tabular}

Bold: individual factors that significantly $(p<0.05)$ influenced the responses.

falling in the good range, which means our second-order polynomial equations, really represented the experimental data. Also, obtaining values of AADM (analysis of the absolute average deviation) and $\mathrm{Bf}$ (Bial factor), respectively, equal to 0 and 0.99 for both total phenolic and flavonoid contents, thus confirming the suitability of the models since values were in the normal range ( 0 for AADM and $0.75<\mathrm{Bf}<1.25$ for $\mathrm{Bf}$ ).

\section{Optimization of the Process}

After validation of the model, the optimal extraction conditions for total phenolic and flavonoid contents were determined using iso-responses and responses surfaces curves. Iso-responses curves are two-dimensional representations showing the variation of a fixed parameter according to two factors. Figures 4(a)-4(d) illustrate the variation in TPC and 


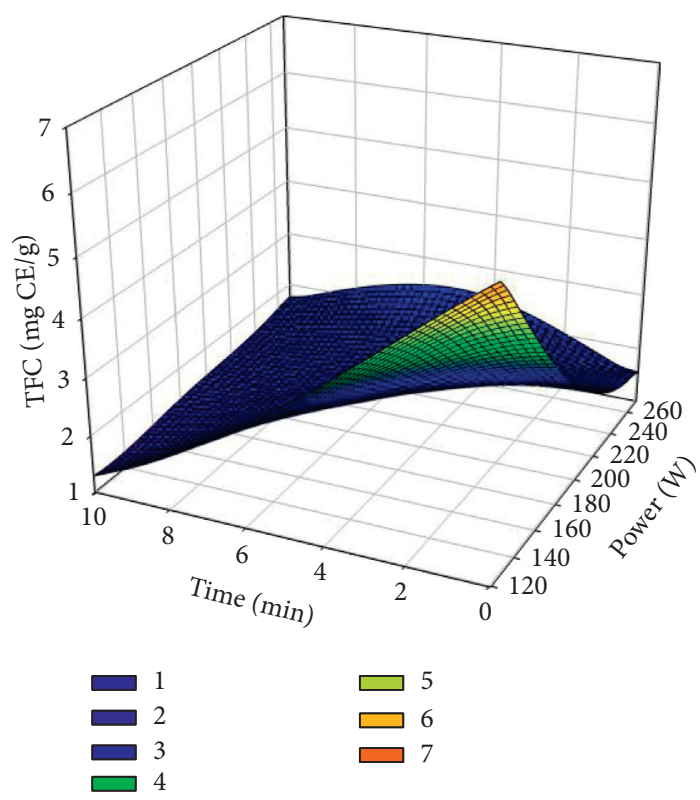

(a)

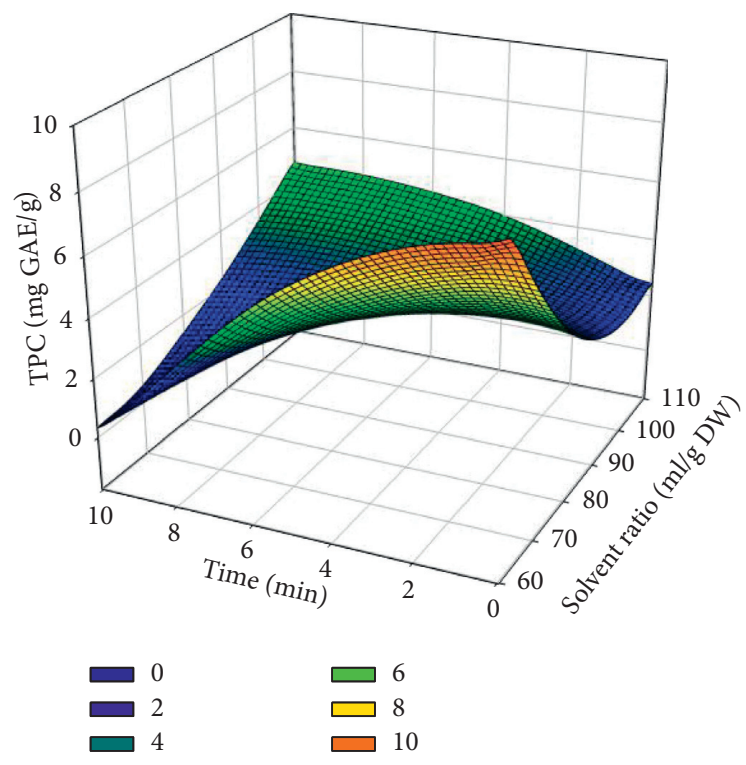

(c)

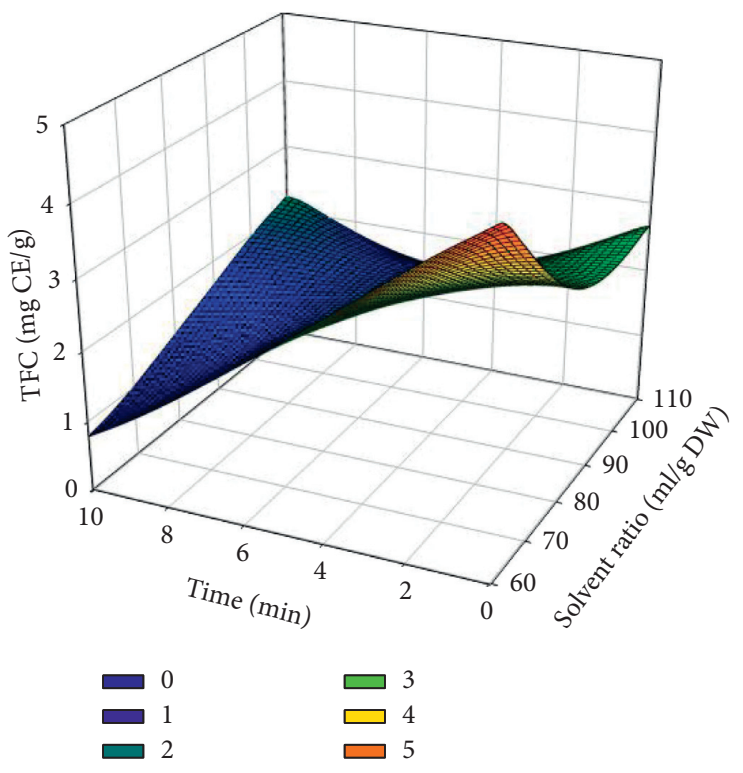

(b)

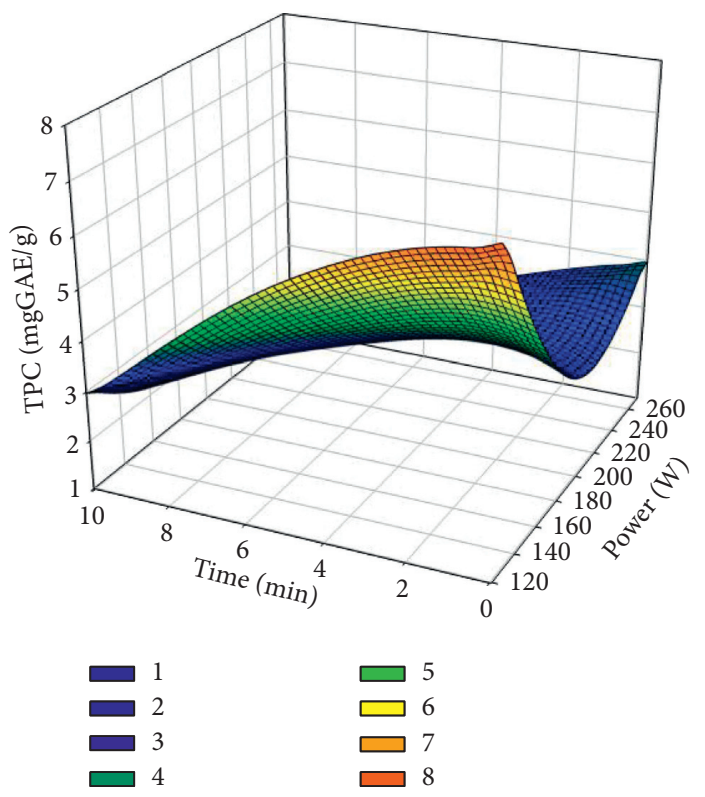

(d)

Figure 4: (a, b, c, and d) Response surface curves for TPC and TFC considering the different factors taken 2 by 2.

TFC of soybean meal extracts under the influence of different factors. These figures show that maximum TPC is obtained at $120 \mathrm{~W}$, with a solvent ratio of $60: 1$ for $0.16 \mathrm{~min}$, and the same for TFC.

\section{Confirmation Experiments}

In order to confirm the quality of our model to predict the optimal conditions for our responses, experiments were made, replicating optimal conditions and results compared with the predicted maximal values in Table 6 . No significant differences were noticed between optimal predicted values and experimental values obtained for TPC and TFC, thus confirming the validity of the predicted optimal values given by the software.

\section{Characterization of the Extract}

8.1. IR Spectral Analysis. The IR spectra of Glycine max seed extract is depicted in Figure 5. Table 7 shows the different absorbance peaks and their assignment. Polyphenols were identified among the compounds present in the extract.

8.2. Thin-Layer Chromatography. Thin-layer chromatography of Glycine max seed extract showed a number of nine bands with Rf going from 0.15 to 0.98 . Two spots were 
TABLE 6: Experimental, predicted values, and desirability for TPC and TFC in optimal conditions.

\begin{tabular}{lccc}
\hline & Optimal predicted value & Optimal experimental value & Desirability \\
\hline Phenol (mg GAE/g) & $13.09^{\mathrm{a}}$ & $12.97 \pm 0.05^{\mathrm{a}}$ & 1.00 \\
Flavonoid (mg CE/g) & $7.39^{\mathrm{a}}$ & $7.42 \pm 0.09^{\mathrm{a}}$ & 1.00 \\
\hline
\end{tabular}

On the same line, values with different letters significantly differ $(p>0.05)$.

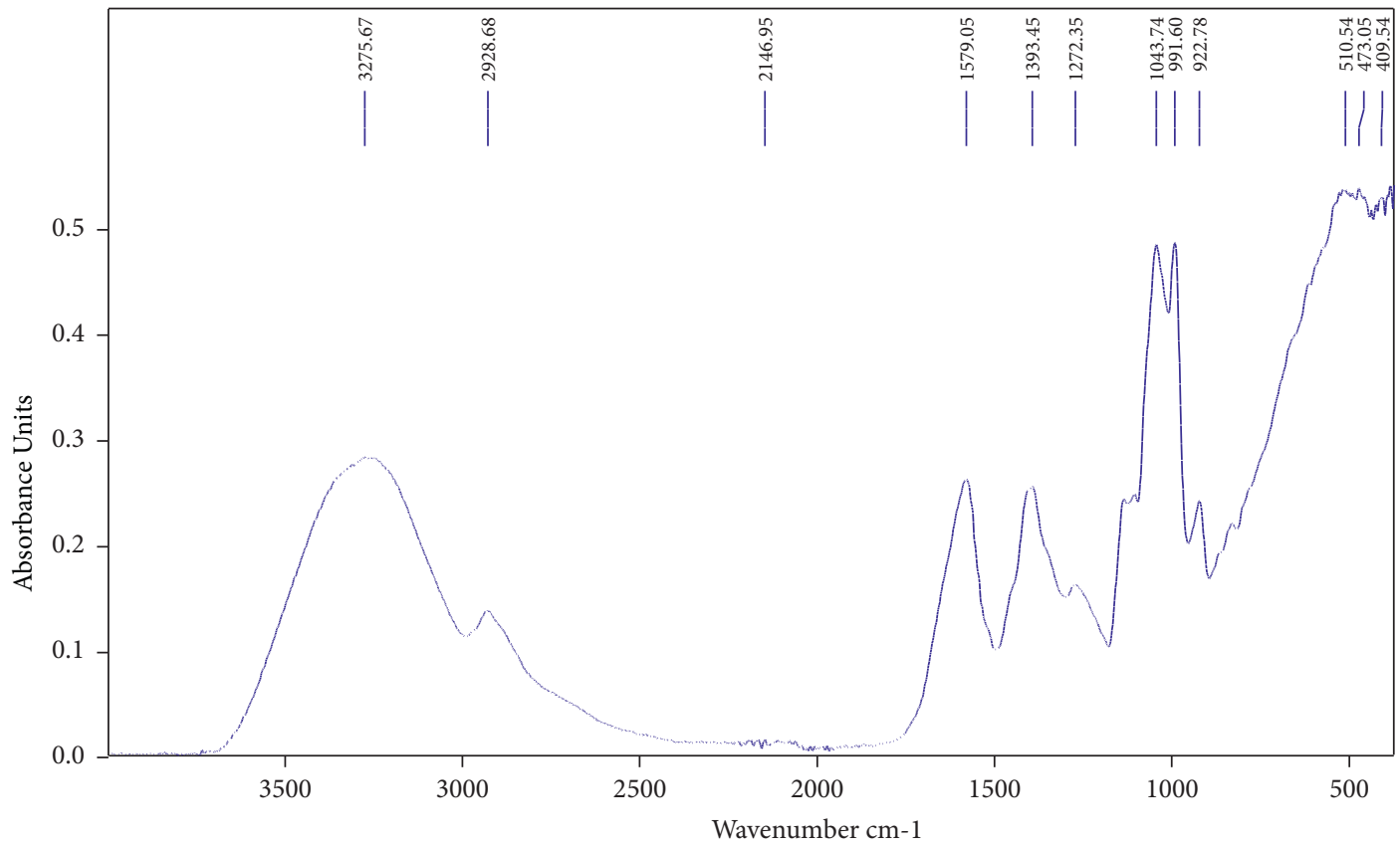

FIGURE 5: FTIR spectra of Glycine max meal extract.

TABLE 7: Peak wave numbers and assignation.

\begin{tabular}{|c|c|c|c|}
\hline Wave number $\left(\mathrm{cm}^{-1}\right)$ & Vibration & Assignment & Reference \\
\hline 3275 & $-\mathrm{C}-\mathrm{OH}$ (stretching) & Water and polysaccharides & {$[30,31]$} \\
\hline 2928 & $-\mathrm{C}-\mathrm{H}$ (stretching) & $\begin{array}{l}\text { Aliphatic chain: lipids } \\
\text { Isoflavones (daidzein and genistein) }\end{array}$ & $\begin{array}{l}{[30]} \\
{[32]}\end{array}$ \\
\hline 2146 & $-\mathrm{NH}_{2}$ (stretching) & Free amino acid and/or derivatives & [33] \\
\hline 1579 & $\begin{array}{l}-\mathrm{C}=\mathrm{C} \text { (skeletal) } \\
-\mathrm{C}-\mathrm{H} \text { (bending) }\end{array}$ & Aromatic compounds and flavonoids & \\
\hline 1393 & $\begin{array}{l}-\mathrm{O}-\mathrm{H} \text { (deformation) } \\
-\mathrm{C}-\mathrm{O} \text { (deformation) }\end{array}$ & Phenols & {$[34]$} \\
\hline 1272 & In plane $=\mathrm{C}-\mathrm{H}$ & Phenols, flavonoids, or aromatic compounds & {$[35]$} \\
\hline 1040 & Ester $-\mathrm{C}-\mathrm{O}$ (stretching) & Glycosidic groups & {$[36]$} \\
\hline 991 & & Unidentified & \\
\hline 922 & -C-C (stretching) & Alkane lipids, aminiacids, and proteins & \\
\hline 510 & Phenol ring (torsion) & Phenols & {$[37]$} \\
\hline 473 & O-S-O (bending) & $\mathrm{SO}^{-4}$ group & {$[38]$} \\
\hline 409 & In plane $-\mathrm{C}-\mathrm{OH}$ (bending) & Phenols & {$[33]$} \\
\hline
\end{tabular}

identified as catechin and quercetin, respectively, those with $\mathrm{Rf}$ of 0.98 and 0.93 . Figure 6 shows the plates with respective spots under UV light and the schematic representation of the plate after development.

TLC revealed the presence of at least nine different compounds or groups of compounds in the obtained extract, with a high relative abundance of quercetin (8). A similar observation was made by Hanan et al. [39] who stated that quercetin is the most abundant flavonoid found in soybean seeds. Rf values of all spots observed under UV light are given in Table 8 .

8.3. Anti-Oxidant Capacity of the Extract. DPPH and FRAP anti-oxidant capacities of the extract were moderate, with a DPPH scavenging $\mathrm{IC}_{50}$ of $194.98 \mu \mathrm{g} / \mathrm{ml}$ and low absorbances at $700 \mathrm{~nm}$ in the FRAP test. Moderate DPPH scavenging activity of soybean seeds extracts has already been reported 


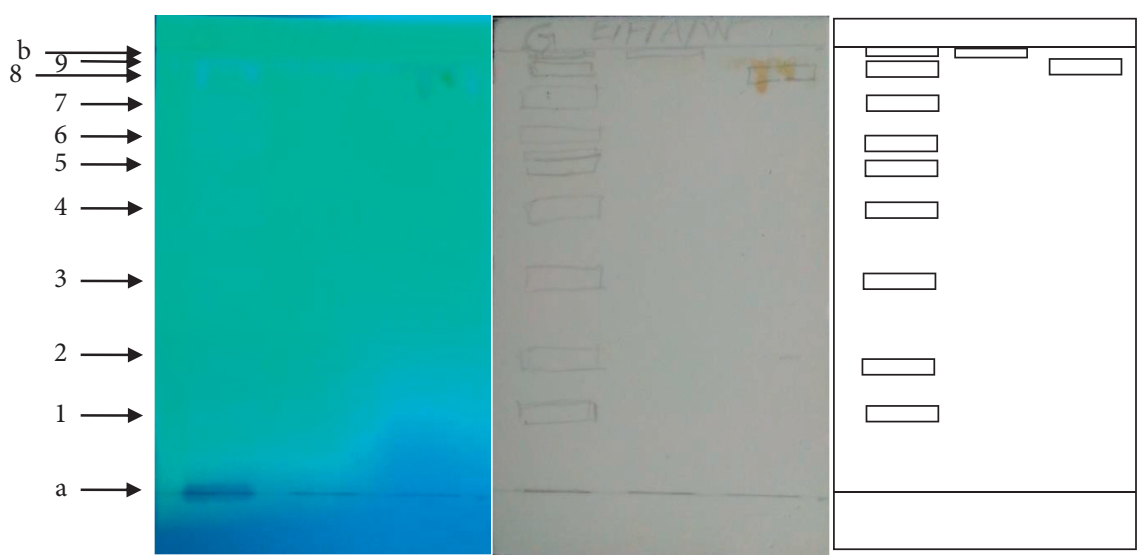

FIGURE 6: Chromatography plates after development: (a) under UV 254 light, (b) under white light with bands circled, and (c) schematic representation. $a=$ deposit line, $b=$ front line, and $1,2,3,4,5,6,7,8$, and 9 are bands observed under UV light.

TABLE 8: Rf values of the compounds of the optimized soybean meal extract.

\begin{tabular}{lccccccccc}
\hline Spots number & 1 & 2 & 3 & 4 & 5 & 6 & 7 & 8 & 9 \\
\hline Rf & 0.15 & 0.29 & 0.46 & 0.72 & 0.78 & 0.8 & 0.89 & 0.93 & 0.98 \\
Identification & - & - & - & - & - & - & - & Quercetin & Catechin \\
\hline
\end{tabular}

TABLE 9: Percentage of DPPH inhibition and FRAP test absorbances.

\begin{tabular}{|c|c|c|c|}
\hline \multirow{2}{*}{ Concentration $(\mu \mathrm{g} / \mathrm{ml})$} & \multicolumn{2}{|c|}{ DPPH scavenging activity } & \multirow{2}{*}{$\begin{array}{c}\text { FRAP } \\
\text { Absorbance at } 700 \mathrm{~nm}\end{array}$} \\
\hline & $\%$ Inhibition & $\mathrm{IC}_{50}(\mu \mathrm{g} / \mathrm{ml})$ & \\
\hline 12.5 & 39.9 & & 0.10 \\
\hline 25 & 47.11 & & 0.36 \\
\hline 50 & 54.38 & 194.98 & 0.47 \\
\hline 100 & 65.09 & & 0.87 \\
\hline 200 & 74.24 & & 1.36 \\
\hline
\end{tabular}

by Djordjevic et al. [40] who found $\mathrm{IC}_{50}>200 \mu \mathrm{g} / \mathrm{ml}$. Table 9 shows DPPH and FRAP inhibitory results of the soybean meal extract.

\section{Conclusion}

The study aimed at determining the optimal conditions for extraction of total phenolic and flavonoid compounds from soybean meal using a green protocol. RSM was used to determine the conditions, and we found out that all factors, namely, solvent ratio, time, and power significantly, influenced both responses. Results suggest that low solvent, power, and time of exposure should be used when attempting to obtain high TPC and TFC extracts from soybean meal with MAE. RSM used in this research permitted us to define the conditions for green extraction of TPC and TFC from soybean waste as: 60/1 solvent/dry matter ratio, $120 \mathrm{~W}$ power, and $0.16 \mathrm{~min}$ time. FTIR confirmed the presence of polyphenolic compounds in the extract obtained, and TLC permitted to identify catechin and quercetin, while DPPH and FRAP tests showed that the obtained extract possesses moderate anti-oxidant capacities. RSM permitted to obtain a polyphenolic rich extract, containing catechin and quercetin, with anti-oxidant capacities, usable in nutraceutical, food, cosmetic and pharmaceutical industries from seeds waste; thus, soybean meal can be well valorized as good source of polyphenols.

\section{Data Availability}

The data are available on request (Woumbo Cerile Ypolyte at woumbocerile@yahoo.fr).

\section{Conflicts of Interest}

The authors declare that there are no conflicts of interest.

\section{Authors' Contributions}

Woumbo Cerile Ypolyte and Kuate Dieudonné conceived the work, collected seeds, carried out experimentations, analyzed and interpreted data, and wrote the paper. Klang Mathilde Julie followed up the work, verified data analysis, and read the paper for correction. Womeni Hilaire Macaire supervised the work and read the paper.

\section{Acknowledgments}

This research did not receive any specific grant from funding agencies in the public, commercial, or not-for-profit sectors. 


\section{References}

[1] N. Dono and E. Indarto, "Soy-milk waste with soybean meal dietary substitution: effects on growth performance and meat quality of broiler chickens," Jurnal Peternakan Indonesia, vol. 19, no. 2, pp. 55-60, 2017.

[2] W. Mo, R. Lau, A. Kwok, and M. Wong, "Use of soybean meal and papain to partially replace animal protein forculturing three marine fish species: fish growth and water quality," Environmental Pollution, vol. 219, pp. 1-6, 2016.

[3] A. Anak, H. Wuryanti, O. Ika, B. Agung, and N. Ni, "Isolation and hydrolysis XylanFrom soybean waste with endo- $\beta-1,4-\mathrm{D}$ xilanase of Bacillus sp. from soil termite abdomen," Agriculture and Agricultural Science Procedia, vol. 9, pp. 371-377, 2016.

[4] G. Nugroho, R. Sulistyaningrum, M. Prastiwa, and H. Widhi, "Environmental analysis of tofu production in the context of cleaner production: case study of tofu household industries in salatiga, Indonesia," Journal of Environmental Science and Sustainable Development, vol. 2, no. 2, pp. 127-138, 2019.

[5] B. N. Bhalkar, P. A. Bedekar, S. D. Kshirsagar, and S. P. Govindwar, "Solid state fermentation of soybean waste and an up-flow column bioreactor for continuous production of camptothecine by an endophytic fungus Fusarium oxysporum," RSC Advances, vol. 6, no. 61, pp. 56527-56536, 2016.

[6] M. Partovi, T. B. Lotfabad, R. Roostaazad, M. Bahmaei, and S. Tayyebi, "Management of soybean oil refinery wastes through recycling them for producing biosurfactant using Pseudomonas aeruginosa MR01," World Journal of Microbiology and Biotechnology, vol. 29, no. 6, pp. 1039-1047, 2013.

[7] M. Thrane, M. Paulsen, and T. Krieger: Soy Protein: Impacts, Production and Application.

[8] T. Duangjai, T. Areeya, P. Apinan, and Y. Aujana, "Medicinal plants for pharmaceutical and medical aspects: an overview," Medicines, vol. 5, pp. 93-109, 2018.

[9] J. You, K. Soon-Jae, Q. Shanshan, K. Dong-Gun, and H. Seok, "Antioxidant contributors in seed, seed coat, and cotyledonof $\gamma$-ray-induced soybean mutant lines with different seed coat colors," Antioxidants, vol. 10, p. 353, 2021.

[10] F. Chemat, N. Rombaut, A. Meullemiestre et al., "Review of green food processing techniques. Preservation, transformation, and extraction," Innovative Food Science \& Emerging Technologies, vol. 41, pp. 357-377, 2017.

[11] S. G. Jahromi, "Extraction techniques of phenolic compounds from plants," Plant physiological aspects of phenolic compounds, pp. 1-18, 2019.

[12] A. Khoddami, M. A. Wilkes, and T. H. Roberts, "Techniques for analysis of plant phenolic compounds," Molecules, vol. 18, no. 2, pp. 2328-2375, 2013.

[13] R. Ciriminna, D. Carnaroglio, R. Delisi, S. Arvati, A. Tamburino, and M. Pagliaro, "Industrial feasibility of natural products extraction with microwave technology," Chemistry, vol. 1, no. 3, pp. 549-555, 2016.

[14] J. F. Osorio-Tobón, "Recent advances and comparisons of conventional and alternative extraction techniques of phenolic compounds," Journal of Food Science \& Technology, vol. 57, pp. 4299-4315, 2020.

[15] V. Mandal, Y. Mohan, and S. Hemalatha, "Microwave assisted extraction-an innovative and promising extraction tool for medicinal plant research," Pharmacognosy Reviews, vol. 1, no. 1, pp. 7-18, 2007.

[16] S. Đurović, B. Nikolić, N. Luković et al., "The impact of highpower ultrasound and microwave on the phenolic acid profile and antioxidant activity of the extract from yellow soybean seeds," Industrial Crops and Products, vol. 122, pp. 223-231, 2018.

[17] D. F. Silva and M. O. O. Rezende, "Microwave-assisted extraction of phenolic compounds from Canavalia ensiformis leaves: preparation and evaluation of prospective bioherbicide on control of soybean weeds," International Journal of Engineering and Applied Sciences, vol. 3, no. 7, p. 257615, 2016.

[18] A. Padmaja and N. Prasad, "Pomegranate (Punica granatum L.) peel extract as a source of natural antioxidant," Journal of Food Science and Engineering, vol. 1, no. 3, pp. 171-183, 2011.

[19] L. Mensor, F. Menezez, G. Leitao et al., "Screning of Brazilian plant extracts for antioxidant activity by the use of DPPH free radical method," Phytotherapy Research, vol. 15, pp. 127-130, 2001.

[20] M. Oyaizu, "Studies on products of browning reaction prepared from glucosamine," Japanese Journal of Nutrition, vol. 44, pp. 307-315, 1986.

[21] G. Inglett, D. Rose, D. Chen, D. Stevenson, and A. Biswas, "Phenolic content andantioxidant activity of extracts from whole buckwheat (FagopyrumesculentumMöench) with or without microwave irradiation," Food Chemistry, vol. 119, pp. 1216-1219, 2010.

[22] Z. Rafiee, S. Jafari, M. Alami, and M. Khomeiri, "Microwaveassisted extraction of phenolic compounds from olive leaves; a comparison with maceration," Journal of Animal and Plant Sciences, vol. 21, no. 4, pp. 738-745, 2011.

[23] N. Rhazi, H. Hannache, M. Oumam et al., "Green extraction process of tannins obtained from Moroccan Acacia mollissima barks by microwave: modeling and optimization of the process using the response surface methodology RSM," Arabian Journal of Chemistry, vol. 12, no. 8, pp. 2668-2684, 2019.

[24] D. Malenčić, M. Popović, and J. Miladinović, "Phenolic content and antioxidant properties of soybean (Glycine max (L.) Merr.) seeds," Molecules, vol. 12, no. 3, pp. 576-581, 2007.

[25] G. Sakthivelu, M. Akitha, P. Giridhar et al., "Isoflavone Composition, Phenolcontent, andantioxidant activity of soybean seeds from Indiaand Bulgaria," Journal of Agricultural and Food Chemistry, vol. 56, pp. 2090-2095, 2008.

[26] A. Josipović, R. Sudar, A. Sudarić, V. Jurković, M. MatošaKočar, and A. MarkuljKulundžić, "Total phenolic and total flavonoid content variability of soybean genotypes in eastern Croatia," Croatian Journal of Food Science and Technology, vol. 8, no. 2, pp. 60-65, 2016.

[27] A. Mohamed and Y. Chang, "Optimization of phenolics and dietary fibre extraction from date seeds," Food Chemistry, vol. 108, pp. 977-985, 2008.

[28] T. Xuan, L. Vo, Q. Tran, G. Long, T. Tran, and T. Pham, "Extraction process of polyphenols from soybean (glycine max 1.) sprouts: optimization and evaluation of antioxidant activity," Processes, vol. 7, p. 489, 2019.

[29] A. Joglekar and A. May, "Product excellence through design of experiments," Cereal Foods World, vol. 32, pp. 857-868, 1987.

[30] K. Kozłowicz, R. Różyło, B. Gładyszewska et al., "Identification of sugars and phenolic compounds in honey powders with the use of GC-MS, FTIR spectroscopy, and X-ray diffraction," Scientific Reports, vol. 10, no. 1, pp. 1-10, 2020.

[31] R. N. Oliveira, M. C. Mancini, F. C. S. D. Oliveira et al., "FTIR analysis and quantification of phenols and flavonoids of five commercially available plants extracts used in wound healing," Matèria. Revista Internacional d'Art, vol. 21, pp. 767-779, 2016.

[32] E. Sulistyowati, S. Martono, S. Riyanto, E. Lukitaningsih, and A. Rohman, "Rapid quantitative analysis of daidzein and 
genistein in soybeans (Glycine max (L). Merr.) using FTIR spectroscopy and multivariate calibration," Journal of Applied Pharmaceutical Science, vol. 20, no. 11, pp. 117-123, 2020.

[33] P. Made and P. Luh, "Phytochemical screening and FTIR spectroscopy on crude extract from enhalusacoroidesleaves," Malaysian journal of analytical sciences, vol. 24, no. 1, pp. 70-77, 2020.

[34] L. Svečnjak, Z. Marijanović, P. Okińczyc, P. Marek Kuś, and I. Jerković, "Mediterranean propolis from the adriatic sea islands as a source of natural antioxidants: comprehensive chemical biodiversity determined by GC-MS, FTIR-ATR, UHPLC-DAD-QqTOF-MS, DPPH and FRAP assay," Antioxidants, vol. 9, no. 4, pp. 337-369, 2020.

[35] C. Danciu, I. Pavel, R. Babuta et al., "Total phenolic content, FTIR analysis, and antiproliferative evaluation of lupin seeds harvest from western Romania," Annals of Agricultural and Environmental Medicine: AAEM, vol. 24, no. 4, pp. 726-731, 2017.

[36] M. J. Baker, J. Trevisan, P. Bassan et al., "Using Fourier transform IR spectroscopy to analyze biological materials," Nature Protocols, vol. 9, no. 8, pp. 1771-1791, 2014.

[37] J. K. Kumar and A. D. Prasad, "Identification and comparison of biomolecules in medicinal plants of Tephrosia tinctoria and Atylosia albicans by using FTIR," Romanian Journal of Biophysics, vol. 21, no. 1, pp. 63-71, 2011.

[38] A. M. Soliman, H. M. Elwy, T. Thiemann, Y. Majedi, F. T. Labata, and N. A. Al-Rawashdeh, "Removal of $\mathrm{Pb}$ (II) ions from aqueous solutions by sulphuric acid-treated palm tree leaves," Journal of the Taiwan Institute of Chemical Engineers, vol. 58, pp. 264-273, 2016.

[39] A. Hanan, R. El-Mergawi, and S. Radwan, "Isoflavonoids, flavonoids, phenolic acids profiles and antioxidant activity of soybean eeds as affected by organic and bioorganic fertilization," American-eurasian Journal of Agricultural \& Environmental Sciences, vol. 4, no. 2, pp. 207-213, 2008.

[40] T. Djordjevic, S. Šiler-Marinkovic, and S. DimitrijevicBrankovic, "Antioxidant activity and total phenolic content in some cereals and legumes," International Journal of Food Properties, vol. 14, no. 1, pp. 175-184, 2016. 